\title{
Optimal Demand Side Bidding with Carbon Emission by Using MRS Strategy
}

\author{
Kaustubh Dwivedi, Yogendra Kumar, and Ganga Agnihotri \\ Department of Electrical Engineering, Maulana Azad National Institute of Technology, Bhopal, India \\ Correspondence should be addressed to Kaustubh Dwivedi; kaustubhd@rediffmail.com
}

Received 6 January 2014; Accepted 19 February 2014; Published 22 April 2014

Academic Editors: I. Smith and Y. Zhu

Copyright ( 2014 Kaustubh Dwivedi et al. This is an open access article distributed under the Creative Commons Attribution License, which permits unrestricted use, distribution, and reproduction in any medium, provided the original work is properly cited.

\begin{abstract}
A new moderate-random-search strategy (MRPSO) is used for an optimal bidding strategy of a supplier, considering linear bidding curve model with a precise model and emission as constraints, and who delivered electricity to end users in oligopolistic dynamic electricity is studied. Bidding strategy of a supplier is solved by MRPSO, where mean best position $\left(m_{\text {best }}\right)$ boosts the diversity and the exploration ability of particle. The MRPSO adopts an attractor $p_{d}$ as the main moving direction of particles, which replaces the velocity update procedure in the particle swarm optimization. The effectiveness of the proposed approach is tested with linear bidding model and the results are compared with the solutions obtained using classical PSO. In this paper, a comparative study has been done by a competitive bidding model tested on IEEE 14- and IEEE 39-bus systems and results motivate the suppliers towards opting green technologies.
\end{abstract}

\section{Introduction}

In this competitive world, the market is to be said perfect only when the seller and buyer both have competition and are participating equally in the competitive bidding process. In energy market, the generation as well as load side has competition in this competitive electricity market. Recently the electricity markets are in transition phase from single buyer and single seller pattern to multibuyer and multiseller pattern. This type of auction system makes an environment for demanding side entities to compete with their opponents through bidding process; moreover the benefits of retailers depend on their participation in the bidding process so developing the optimal bidding strategies of demanding side is of keen interest in recent researches.

In this emerging electricity market, each power supplier can increase its own profit through strategic bidding. The imperfect knowledge of rival suppliers extensively affects the profit of each supplier [1]. In the day-ahead electricity market bids have been submitted to the market operator, who matches generation level of each participant for hourly aggregate supply and decides market clearing prices (MCP). The framing of best optimal bids for supplier with their own costs, technical constraints, and behavior of rival's and market is known as strategic bidding problem. Lots of work has been done on strategic bidding in competitive electricity market. There are some approaches to frame the strategic bidding problem (SBP) on the basis of their MCP and rival's bidding behavior [2]. A basic model of optimal bidding has been framed firstly, solved by using dynamic programming based technique [3]. A strategic bidding problem has been solved by Lagrangian relaxation based approach in [4] and the same has been suggested by Zhang et al. for daily bidding and self-scheduling decision [5]. In [6] SBP in oligopolistic dynamic electricity double-sided auctions is solved by using Nash-Cournot strategies for the market participants. The Reanalysis has been done for Nash Equilibrium Bidding Strategies in a Bilateral Electricity Market in [7]. Ugedo et al. [8] have proposed a stochastic-optimization model for submitting the block bids to obtain the distribution of the electricity resources of a generation firm among the different sequential markets within a wholesale electricity market. 
In [9] a genetic algorithm evolves a framework in which bidding strategies may be tested and modified. In [10] authors have extended the same approach price based UC formulation for competitive market. In [11] author has proposed two different bidding schemes by using genetic algorithm. The same approach for spinning reserve market coordinated with energy market has been suggested by Wen and David [12]. The heuristics approaches such as Evolutionary AlgorithmBased Hybrid Approach [13], fuzzy mixed integer linear programming [14], simulated annealing [15], and combination of these are used to obtain a global solution for strategic bidding problems [16]. These heuristics approaches are commonly restricted by their receptivity to the choice of parameters, such as the crossover and mutation probabilities, in GA, temperature in SA, scaling factor in EP, and inertia weight and learning factors in PSO. In [17] a moderate-random-search (MRS) strategy is introduced into the new PSO algorithm with a view to enhance its global search ability and improves the convergence rate for the particle.

In the unit commitment and monetary evaluation of power plants, the price of emissions is one of the decisive factors. Authors investigate an influence of emission constraints on generation scheduling and solving of the new profit-based UC problem with carbon trading [16, 18-20]. Hence, it is essential to investigate the resulting market price for emissions [21].

Lots of work has been done with PSO in strategic bidding for competitive electricity market $[22,23]$ but the growing issue of emissions from generation of electricity, which affects environmentally, socially, and economically all mankind, is not being discussed yet with PSO. In this paper it is proposed to control $\mathrm{CO}_{2}$ emissions by providing economic penalty for achieving reductions in the $\mathrm{CO}_{2}$ emissions with MRPSO.

\section{Problem Formulations}

2.1. Bidding Model. Linear bid model of electricity market has been considered in the present work. In a linear bid model, the bid curve has been submitted by the retailer which relates the power output with market clearing price $(p)$. The supply bid curve for any bidder " $b$ " can be characterized as $q_{b}(p)=p / m_{b}$, where $q_{b}(p)$ is the output power at price " $p$ " and $m_{b}$ is referred to as the slope of supply bid curve. Onepart price-bid [22] format is considered, in which retailers bid only independent prices for each hour, and a simple market clearing process based on the intersection of supply and demand bid curves is used to determine the winning bids. In a trading session, the system generation is supposed to be insensitive to change in price. This paper considered sealed-bid, pay-as-bid auction mechanism. It is also assumed that the bidders are having the knowledge regarding system generation, number of bidders, and network configuration.

Assume that there are " $n$ " number of independent retailers to purchase their power requirements in an electricity market, where all $(n-1)$ independent retailers (opponents) are integrated into a single entity. The linear supply bid curve for retailer " $R$ ” and opponent expressed by (1) and (2), respectively, is as follows:

$$
\begin{aligned}
& q_{R}=\frac{p}{m_{R}}, \\
& q_{O}=\frac{p}{m_{O}},
\end{aligned}
$$

where " $m_{R}$ " is the slope of supply curve within the limits of $\left[m_{R_{\min }}, m_{R_{\max }}\right]$ and " $m_{\mathrm{O}}$ " is the slope of cumulative linear supply curve of opponents in the range $\left[m_{O_{\min }}, m_{O_{\max }}\right]$. The augmented demand of all the retailers will be

$$
Q=\left(\frac{m_{R}+m_{O}}{m_{R} * m_{O}}\right) * p .
$$

On the basis of proportionate sharing rule, the individual quantity can be defined as $q_{R}$ and $q_{O}$, respectively,

$$
\begin{gathered}
q_{R}=\left(\frac{m_{O}}{m_{R}+m_{O}}\right) * Q, \\
q_{O}=\left(\frac{m_{R}}{m_{R}+m_{O}}\right) * Q .
\end{gathered}
$$

Here " $Q$ " is the total demand quantity by the " $n$ " independent retailers. The objective function and constraints for minimization can be expressed as

$$
\begin{gathered}
\operatorname{Min} \quad\left(m_{R} * q_{R}-c\left(q_{R}\right)+\mathbb{C}\left(q_{R}\right)\right) * q_{R} \\
\text { s.t. } \quad\left[\begin{array}{c}
m_{R_{\min }} \leq m_{R} \leq m_{R_{\max }} \\
m_{\mathrm{O}_{\min }} \leq m_{\mathrm{O}} \leq m_{\mathrm{O}_{\max }} \\
q_{R_{\min }} \leq q_{R} \leq q_{R_{\max }} \\
q_{\mathrm{O}_{\min }} \leq q_{O} \leq q_{\mathrm{O}_{\max }} \\
q_{R}^{\text {sold }}-q_{R}^{\text {bou }}+\boldsymbol{\epsilon}_{R}^{\mathrm{CO}_{2}} * q_{R}=A_{R}^{\mathrm{CO}_{2}} \\
q_{R}^{\text {sold }} \geq 0 \\
q_{R}^{\text {bou }} \geq 0,
\end{array}\right],
\end{gathered}
$$

where $c\left(q_{R}\right)$ is the retailers' cost function which is a function of demand and expressed as

$$
c\left(q_{R}\right)=a_{0}+a_{1} q_{R}+a_{2} q_{R}^{2} .
$$

$A_{G}^{\mathrm{CO}_{2}}$ is the yearly $\mathrm{CO}_{2}$ allowance and $\mathbb{C}\left(q_{R}\right)$ is the emission cost function expressed as

$$
\mathbb{C}\left(q_{R}\right)=\epsilon_{G}^{\mathrm{CO}_{2}} * q_{R} .
$$

\section{MRPSO}

3.1. MRS Strategy. The MRS strategy has been used with PSO algorithm for improving the global search ability of the PSO without slowing down its convergence rate. In this strategy, only position update equation is used. The position $X_{r}^{k+1}$ of 


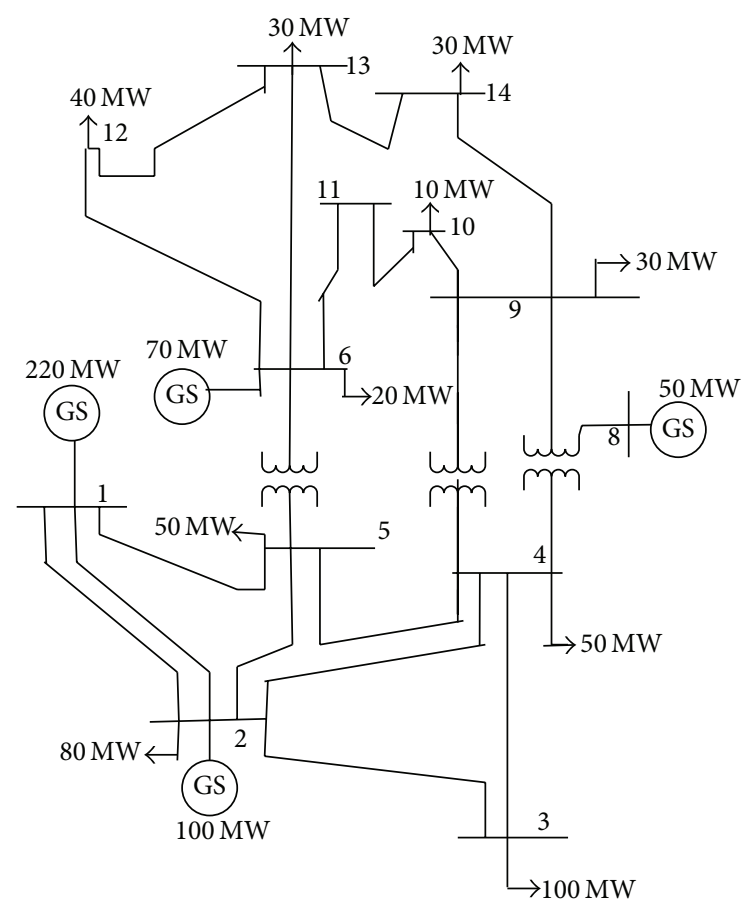

FIgURe 1: 10-user IEEE 14-bus system.

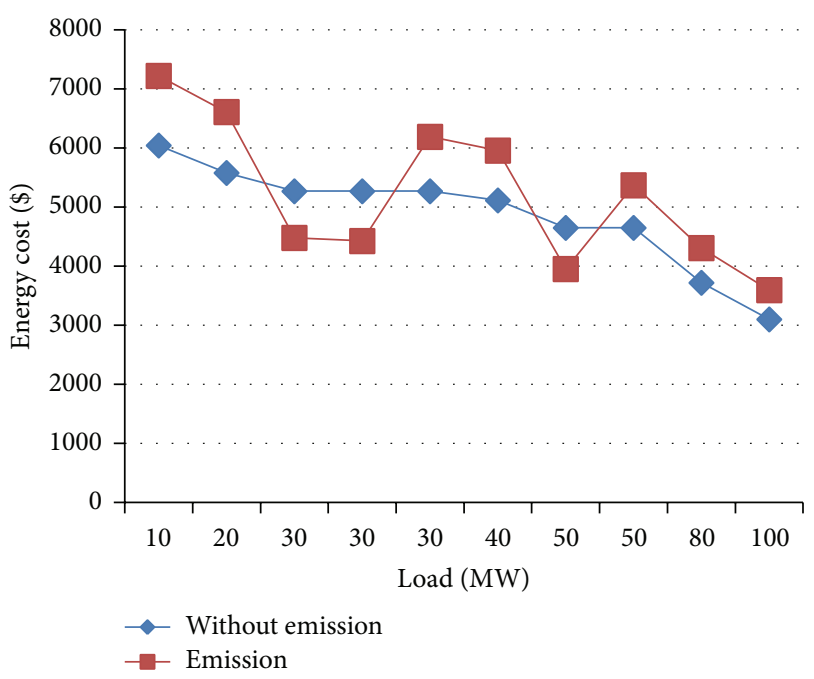

FIGURE 2: Energy cost variation using MRPSO for IEEE 14-bus system.

the $r$ th particle at the $(k+1)$ th iteration can be calculated by using the following formula:

$$
X_{r}^{k+1}=P_{d}+\left[\alpha^{k} * \gamma\left(m_{\text {best }_{r}}-X_{r}^{k}\right)\right] .
$$

In the MRPSO, an attractor $P_{d}$ is used as the main moving direction of particles due to the system convergence to its one and only local attractor of points. It is described as

$$
P_{d}=\operatorname{rand}_{0} * P_{\text {best }_{r}}+\left(1-\operatorname{rand}_{0}\right) G_{\text {best }},
$$

where $\operatorname{rand}_{0}$ is a uniformly distributed random variable varying within $[0,1]$. Attractor " $P_{d}$ " varies within the range

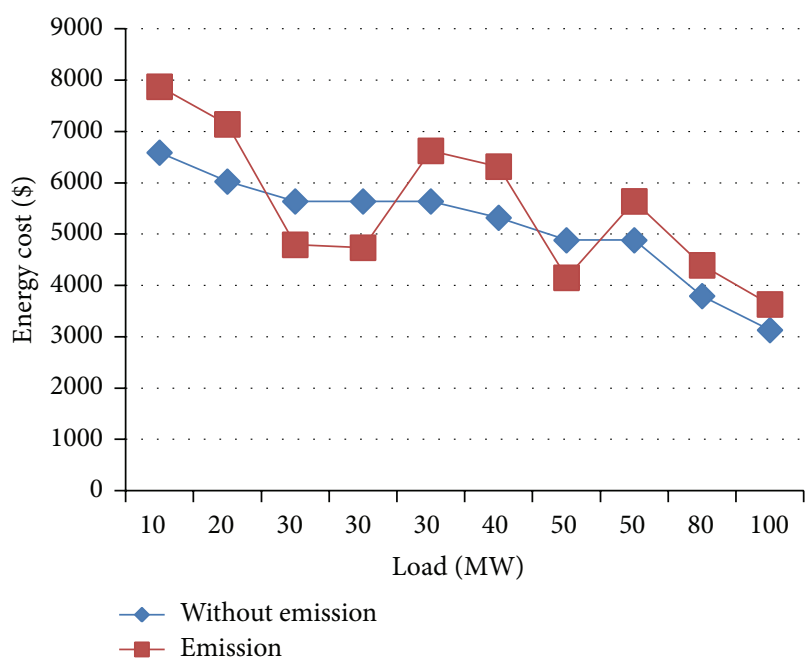

FIGURE 3: Energy cost variation using PSO for IEEE 14-bus system.

$[1,2]$ during iterations. The $m_{\text {best }}$ term used in (10) is called the mean best position [17] which provides the step size for the particle movement and makes the participation of all $P_{\text {best }_{r}}$ to the evolution of particles. Then, it improves the multiplicity and the searching ability of particle. The $m_{\text {best }}$ term is calculated using the following equation:

$$
m_{\text {best }}=\sum_{i=1}^{S} \frac{P_{\text {best }_{i}}}{S},
$$

where $S$ denotes the population size in the MRPSO. $\gamma$ used in (10) represents the random property of the MRPSO.

The value of $\gamma$ is calculated from

$$
\gamma=\frac{\operatorname{rand}_{1}-\operatorname{rand}_{2}}{\operatorname{rand}_{3}} .
$$

$\operatorname{rand}_{1}$ and $\operatorname{rand}_{2}$ are two random variables within $[0,1]$. $\operatorname{rand}_{3}$ is a random variable within $[-1,1]$.

The convergence rate of the MRPSO can be controlled during iterations by $\alpha^{k}$, which works similarly as inertia weight used in the PSO. For better searching ability of particles, " $\alpha$ " is tuned for higher value and lower value gives more precise searching ability. The following LD formula is suggested for the correct selection of " $\alpha$ ":

$$
\alpha^{k}=\alpha_{\max }-\frac{\alpha_{\max }-\alpha_{\min }}{k_{\max }} * k,
$$

where the values are set in the range $0.35 \leq \alpha \leq 0.45$.

3.2. MRPSO Algorithm for Bidding Problem. For the bidding problem position of each particle " $r$ " of generator " $G$ " is represented by the slope of the supply curve $X_{r}=m_{G}^{r}$. The fitness function for each particle is the benefit of generator " $G$ " in (6). The MRPSO algorithm, for the bidding-search process, is as follows.

Step 1. Define input parameters with all constraints for the swarm. 


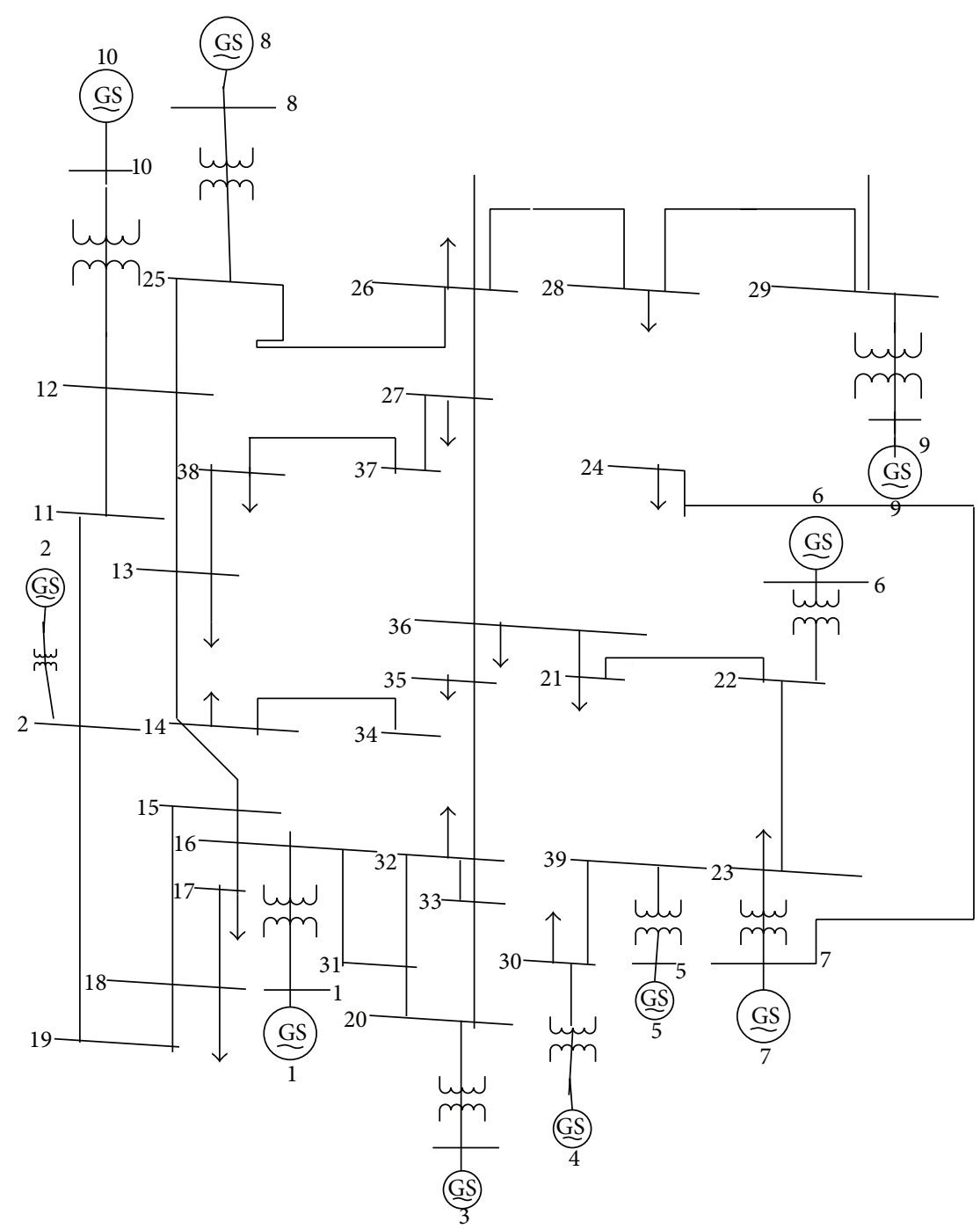

FIGURE 4: 19-user IEEE 39-bus system.

Step 2. Initialize the position $\left(m_{G}\right)$ for all particles randomly with satisfying all the constraints.

Step 3. Find supply quantity of Generator " $G$ ” for randomly generated position $\left(m_{G}\right)$ using $(4)$.

Step 4. Calculate the fitness value (benefit) of each particle in the swarm using fitness function (6).

Step 5. Compare the fitness value of each particle found in Step 4 with $P_{\text {best }}$ of each particle. Update $P_{\text {best }}$ of a particle if its fitness is greater than its $P_{\text {best }}$.

Step 6. Update $G_{\text {best }}$ if any particle has greater fitness than fitness of current $G_{\text {best }}$.

Step 7. Update the attractor " $P_{d}$ " by using (11).

Step 8. Calculate the values of " $m_{\text {best }}$ " from (12), " $\gamma$ " from (13), and " $\alpha$ " from (14).
Step 9. Modify the position of each particle by using (10) with the updated value of attractor in Step 7.

Step 10. Check iteration counter; if it reaches its maximum, then go to Step 11; else go to Step 3.

Step 11. The swarm that generates the latest $G_{\text {best }}$ in Step 6 is the optimal value.

\section{Case Studies}

Let Retailer " $R$ ", for which the linear bid curve is taken as $q_{b}(p)=p / m_{b}$, with the minimum and maximum limits on slope of offer curve as $0.5 \leq m_{G} \leq 1.5$ The retailer cost coefficients used in (8) are taken as $a_{0}=0, a_{1}=2$, and $a_{2}=0.1$. The required demand quantity of retailer is within the limit of $0 \leq q_{R} \leq 1000$. Tables 1 and 2 show the comparison for energy cost of retailer " $R$ " with and 
TABLE 1: Comparison betweenenergy costs (in \$) (50 particles, 100 iterations).

\begin{tabular}{lccccc}
\hline \multicolumn{2}{l}{ IEEE } & 14-bus system & \multicolumn{2}{c}{ Without emission } & \multicolumn{2}{c}{ With emission } \\
Users & Load (MW) & MRPSO & PSO & MRPSO & PSO \\
\hline L2 & 80 & 3720 & 3794 & 4308 & 4394 \\
L3 & 100 & 3100 & 3131 & 3596 & 3632 \\
L4 & $\mathbf{5 0}$ & $\mathbf{4 6 5 0}$ & $\mathbf{4 8 8 2}$ & $\mathbf{3 9 5 3}$ & $\mathbf{4 1 5 1}$ \\
L5 & 50 & 4650 & 4882 & 5371 & 5640 \\
L6 & 20 & 5580 & 6026 & 6612 & 7141 \\
L9 & $\mathbf{3 0}$ & $\mathbf{5 2 7 0}$ & $\mathbf{5 6 3 9}$ & $\mathbf{4 4 8 0}$ & $\mathbf{4 7 9 4}$ \\
L10 & 10 & 6045 & 6589 & 7224 & 7874 \\
L12 & 40 & 5115 & 5320 & 5959 & 6317 \\
L13 & $\mathbf{3 0}$ & $\mathbf{5 2 7 0}$ & $\mathbf{5 6 3 9}$ & $\mathbf{4 4 2 7}$ & $\mathbf{4 7 3 7}$ \\
L14 & 30 & 5270 & 5639 & 6192 & 6625 \\
\hline
\end{tabular}

TABLE 2: Comparison between energy costs (in \$) (50 particles, 100 iterations).

\begin{tabular}{lccccc}
\hline \multicolumn{2}{l}{ IEEE } & 39-bus system & \multicolumn{2}{c}{ Without emission } & \multicolumn{2}{c}{ With emission } \\
Users & Load (MW) & MRPSO & PSO & MRPSO & PSO \\
\hline L3 & 322 & 1349 & 1393 & 1531 & 1577 \\
L4 & 500 & 1077 & 1131 & 1239 & 1301 \\
L7 & 233 & 1475 & 1509 & 1656 & 1695 \\
L8 & 522 & 1044 & 1099 & 1206 & 1269 \\
L12 & 7.5 & 6983 & 6988 & 7733 & 7740 \\
L15 & 320 & 1352 & 1395 & 1534 & 1580 \\
L16 & 329 & 1338 & 1382 & 1519 & 1566 \\
L18 & 158 & 1767 & 1795 & 1970 & 2003 \\
L20 & 628 & 883 & 938 & 1039 & 1091 \\
L21 & 274 & 1422 & 1461 & 1600 & 1647 \\
L23 & 247 & 1463 & 1499 & 1645 & 1682 \\
L24 & 308 & 1370 & 1412 & 1555 & 1597 \\
L25 & 224 & 1499 & 1533 & 1686 & 1721 \\
L26 & 139 & 1738 & 1762 & 1938 & 1963 \\
L27 & 281 & 1412 & 1452 & 1593 & 1638 \\
L28 & 206 & 1526 & 1557 & 1709 & 1745 \\
L29 & 283 & 1407 & 1447 & 1583 & 1633 \\
L31 & 532 & 1181 & 1244 & 1364 & 1435 \\
L39 & 1000 & 758 & 783 & 823 & 853 \\
\hline
\end{tabular}

TABle 3: Computation time (in seconds) for 50 particles, 100 iterations.

\begin{tabular}{lcccc}
\hline & \multicolumn{2}{c}{ Without emission } & \multicolumn{2}{c}{ With emission } \\
& MRPSO & Classical PSO & MRPSO & Classical PSO \\
\hline $\begin{array}{l}\text { IEEE 14-bus } \\
\text { system }\end{array}$ & 0.07383 & 0.09362 & 0.07446 & 0.09697 \\
$\begin{array}{l}\text { IEEE 39-bus } \\
\text { system }\end{array}$ & 0.14974 & 0.19856 & 0.15043 & 0.20016 \\
\hline
\end{tabular}

without consideration of emission coefficient. Table 3 gives the computation time for both techniques. Parameters are tested for 50 particles with 100 iterations with MRS strategy compared with classical-PSO [24]. Both techniques have been tested on 10-user IEEE 14-bus system and 19-user IEEE 39-bus (New England) system by using MATLAB program (see Figure 4). These case studies are based on DC power flow and losses are neglected.

Case I (4-machine IEEE 14-bus system). This test system consists of four generators at buses $1,2,6$, and 8 and ten users at buses $2,3,4,5,6,9,10,12,13$, and 14 . The diagram for 14-bus system was shown in Figure 1.

In this case, it is assumed that users "4" and "9" preferred power from hydel technology and user "13" is giving preference for power from solar-PV technology for low emission charges. MRPSO gives better result for the load variation between 0 and $100 \mathrm{MW}$. The retailers, who take green initiative, also benefitted from the same amount of energy which is used for emissive environment.

Figures 2 and 3 show variation in cost of energy with MRS strategy and classical PSO, respectively, for IEEE 14bus system with and without emission. The valleys show the benefits of preferring green technologies which motivates retailers to use more power coming from the low emissive coefficients technologies. The deep valleys in curve show that the preference of user varied from coal to hydel and then to solar-PV. Table 1 shows cost analysis of ten users of IEEE 14bus system and also distinguished the energy cost of various technologies for the same quantity which motivates taking the green initiatives and cutting down the usage of high carbon emissive technologies.

Case II (10-machine IEEE 39-bus system (New England)). This test system consists of ten generators and 19 users at buses $2,3,4,5,6,9,10,12,13$, and 14. The diagram for 14-bus system was shown in Figure 2.

Figures 5 and 6 show variation in cost of energy with MRS strategy and classical PSO, respectively, for IEEE 39-bus system with and without emission. As the demand for energy is very low, the cost of energy for small users is very high and as the demand increases, the cost would be drastically decreasing and afterwards changes very slowly. Table 2 gives the cost analysis of various users of IEEE 39-bus systems with the help of MRPSO and PSO with emissive and nonemissive environment.

Table 3 gives the computation time for both techniques. Parameters are tested for 50 particles with 100 iterations with MRS strategy compared with classical PSO for IEEE 14- and IEEE 39-bus systems.

\section{Conclusion}

In this Paper, the work is mainly concerned with the development of a mathematical model for generation planning including investment, different cost components, and existing regulatory requirements such as emission. For competitive electricity market, the MRPSO has been applied and compared with the classical PSO for strategic bidding of an electricity supplier with the consideration of carbon emission. A linear bidding model has been postulated with the inclusion of the imperfect bidding behavior of the rivals. 


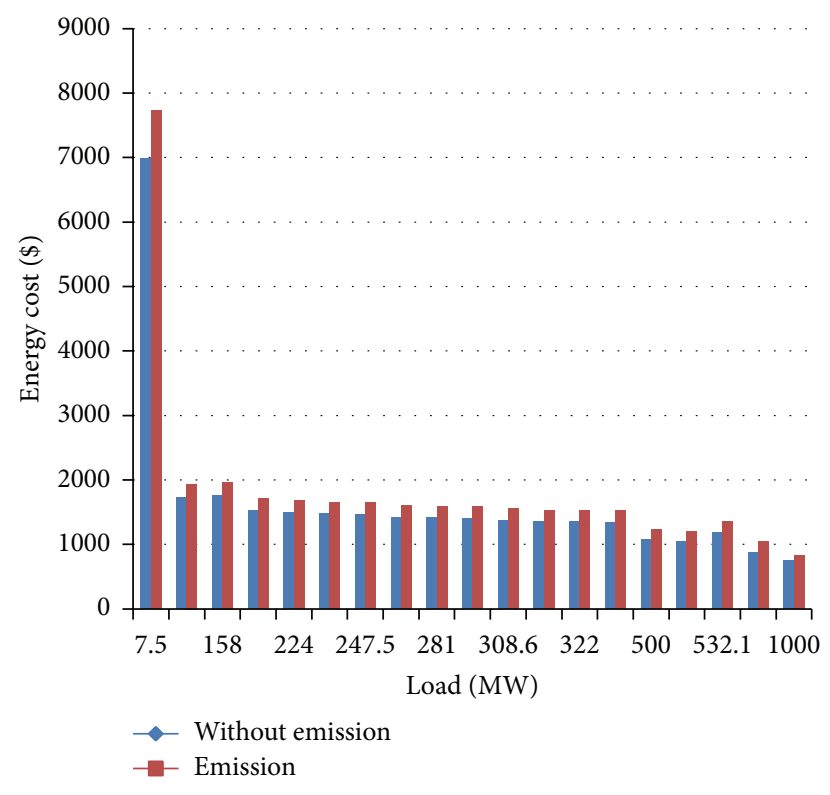

FIGURE 5: Energy cost variation using MRPSO for IEEE 39-bus system.

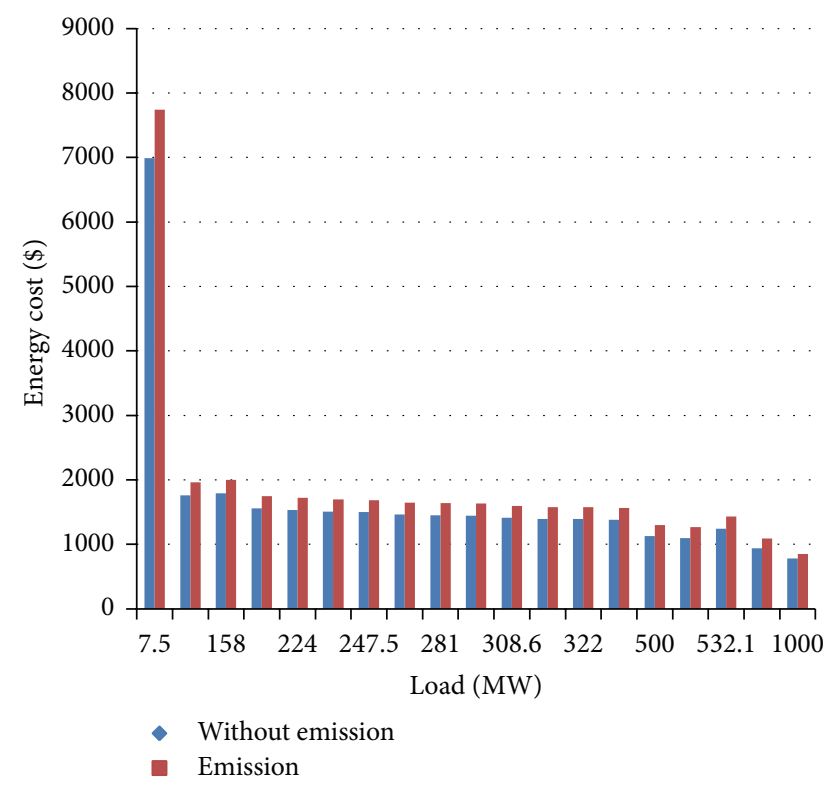

FIgURE 6: Energy cost variation using classical PSO for IEEE 39-bus system.

In this Paper MRPSO gives the improved solution with less computation of time for this continuous type of mathematical model. The MRPSO has worked efficiently for getting energy cost of 10-user IEEE 14- and 19-user IEEE 39-bus systems. The results show that energy cost is higher with emission consideration, so when the cost of carbon is accounted to be low for nonemissive technologies generation, the situation will become worse and the price is much greater than what only convergence of costs would require, but the concern over an imperfect electricity market paired with emissions trading is justified.

\section{Conflict of Interests}

The authors declare that there is no conflict of interests regarding the publication of this paper.

\section{References}

[1] F. Wen and A. K. David, "Optimal bidding strategies and modeling of imperfect information among competitive generators," IEEE Transactions on Power Systems, vol. 16, no. 1, pp. 15-21, 2001.

[2] A. K. David and F. Wen, "Strategic bidding in competitive electricity markets: a literature survey," IEEE PES Summer Meeting, vol. 4, pp. 2168-2173, 2000.

[3] A. K. David, "Competitive bidding in electricity supply," IEE Proceedings C: Generation Transmission and Distribution, vol. 140, no. 5, pp. 421-426, 1993.

[4] G. Gross and D. J. Finlay, "Optimal bidding strategies in competitive electricity markets," in Proceedings of the 12th Power System Computation Conference, pp. 815-823, August 1996.

[5] D. Zhang, Y. Wang, and P. B. Luh, "Optimization based bidding strategies in the deregulated market," in Proceedings of the IEEE PES Power Industry Computer Applications Conference, pp. 6369, May 1999.

[6] A. R. Kian, J. B. Cruz Jr., and R. J. Thomas, "Bidding strategies in oligopolistic dynamic electricity double-sided auctions," IEEE Transactions on Power Systems, vol. 20, no. 1, pp. 50-58, 2005.

[7] Y. S. Son, R. Baldick, and S. Siddiqi, "Reanalysis of nash equilibrium bidding strategies in a bilateral electricity market," IEEE Transactions on Power Systems, vol. 19, no. 2, pp. 12431244, 2004.

[8] A. Ugedo, E. Lobato, A. Franco, L. Rouco, J. FernándezCaro, and J. Chofre, "Strategic bidding in sequential electricity markets," IEE Proceedings: Generation, Transmission and Distribution, vol. 153, no. 4, pp. 431-442, 2006.

[9] C. W. Richter, "Genetic algorithm evolution of utility bidding strategies for the competitive marketplace," IEEE Transactions on Power Systems, vol. 13, no. 1, pp. 256-261, 1998.

[10] C. W. Richter Jr., "A profit-based unit commitment ga for the competitive environment," IEEE Transactions on Power Systems, vol. 15, no. 2, pp. 715-721, 2000.

[11] F. S. Wen and A. K. David, "Strategic bidding for electricity supply in a day-ahead energy market," Electric Power Systems Research, vol. 59, no. 3, pp. 197-206, 2001.

[12] F. S. Wen and A. K. David, "Optimally co-ordinated bidding strategies in energy and ancillary service markets," IEE Proceedings: Generation, Transmission and Distribution, vol. 149, no. 3, pp. 331-339, 2002.

[13] M. L. Wong and K. S. Leung, "An efficient data mining method for learning Bayesian networks using an evolutionary algorithm-based hybrid approach," IEEE Transactions on Evolutionary Computation, vol. 8, no. 4, pp. 378-404, 2004.

[14] B. Venkatesh, T. Jamtsho, and H. B. Gooi, "Unit commitmenta fuzzy mixed integer Linear Programming solution," IET Generation, Transmission and Distribution, vol. 1, no. 5, pp. 836846, 2007.

[15] D. N. Simopoulos, S. D. Kavatza, and C. D. Vournas, "Unit commitment by an enhanced simulated annealing algorithm," IEEE Transactions on Power Systems, vol. 21, no. 1, pp. 68-76, 2006. 
[16] T. C. Ou, K. H. Lu, W. M. Lin, and C. M. Hong, "A study for price-based unit commitment with carbon trading by DI\&C simulation," in Proceedings of the 8th IEEE International Conference on Industrial Informatics, pp. 73-78, July 2010.

[17] H. Gao and W. Xu, "A new particle swarm algorithm and its globally convergent modifications," IEEE Transactions on Systems, Man, and Cybernetics B: Cybernetics, vol. 41, no. 5, pp. 1334-1351, 2011.

[18] I. Kockar, "Unit commitment for combined pool/bilateral markets with emissions trading," in Proceedings of the IEEE Power and Energy Society General Meeting: Conversion and Delivery of Electrical Energy in the 21st Century, pp. 1-9, July 2008.

[19] T. Gjengedal, "Emission constrained unit-commitment (ECUC)," IEEE Transactions on Energy Conversion, vol. 11, no. 1, pp. 132-138, 1996.

[20] Kockar, A. J. Conejo, and J. R. McDonald, "Influence of the emissions trading scheme on market clearing," in Proceedings of the Power System Computation Conference (PSCC '08), 2008.

[21] C. Genesi, G. P. Granelli, P. Marannino et al., "Impact of renewable energy quotas and emission trade on generation planning," in Proceedings of the IEEE Bucharest PowerTech: Innovative Ideas Toward the Electrical Grid of the Future, July 2009.

[22] P. Bajpai, S. K. Punna, and S. N. Singh, "Swarm intelligencebased strategic bidding in competitive electricity markets," IET Generation, Transmission and Distribution, vol. 2, no. 2, pp. 175184, 2008.

[23] P. Bajpai and S. N. Singh, "Fuzzy adaptive particle swarm optimization for bidding strategy in uniform price spot market," IEEE Transactions on Power Systems, vol. 22, no. 4, pp. 21522160, 2007.

[24] K. Dwivedi, Y. Kumar, and G. Agnihotri, "Competitive bidding in electricity markets with carbon emission by using particle swarm optimization," in Proceedings of the IAENG International Conference Electrical Engineering, HongKong, March 2012. 

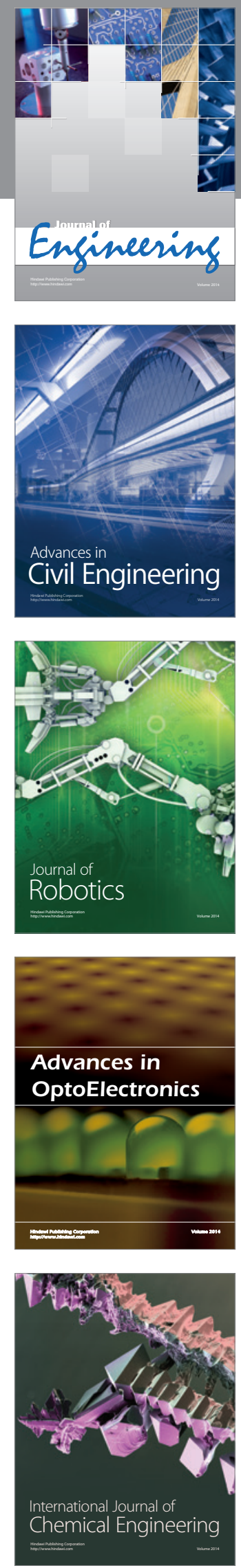

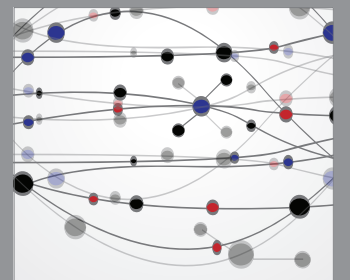

The Scientific World Journal
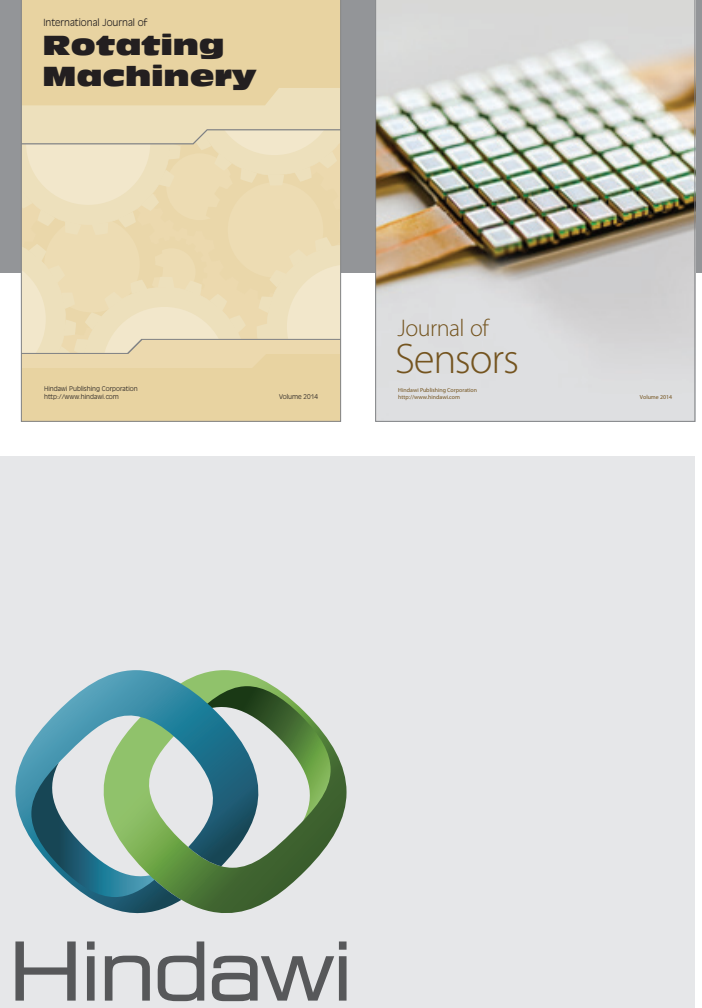

Submit your manuscripts at http://www.hindawi.com
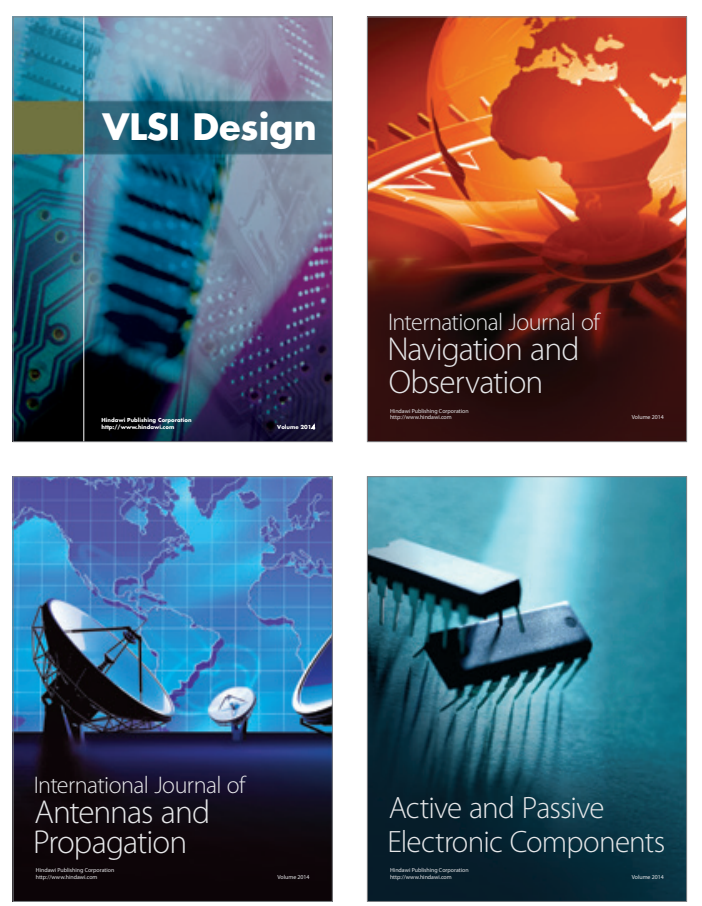
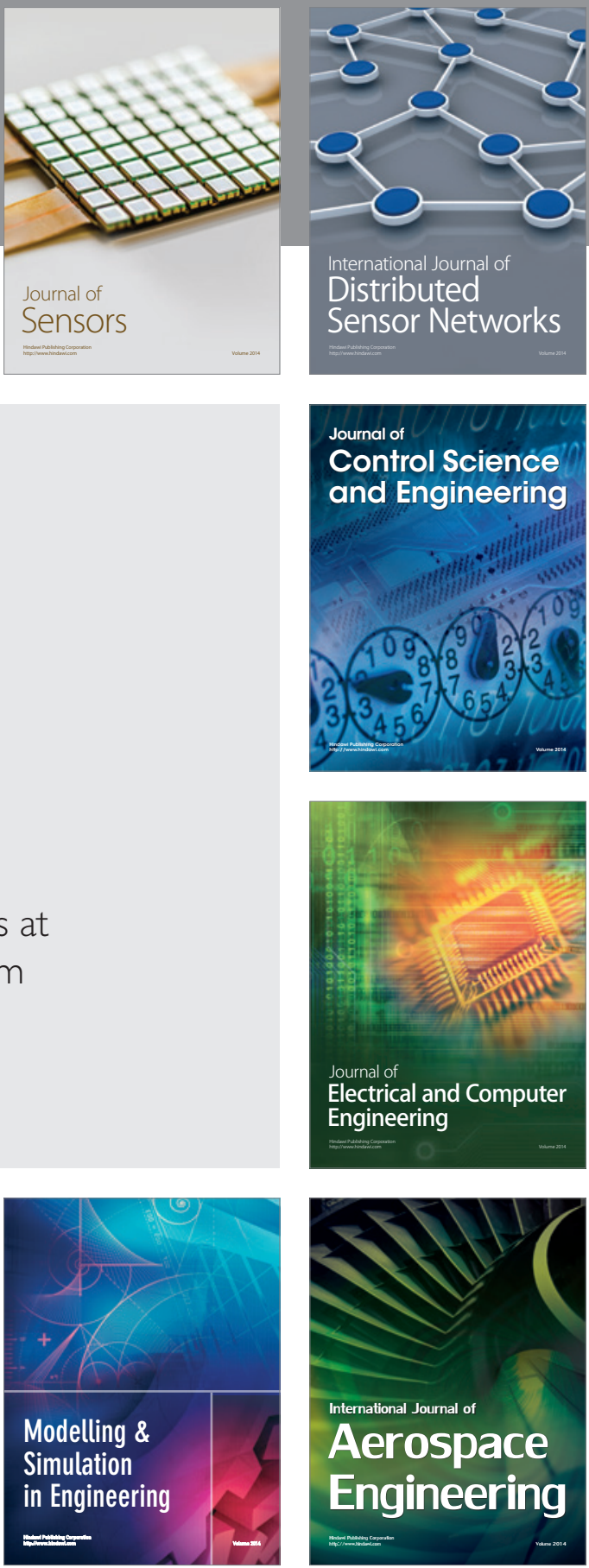

Journal of

Control Science

and Engineering
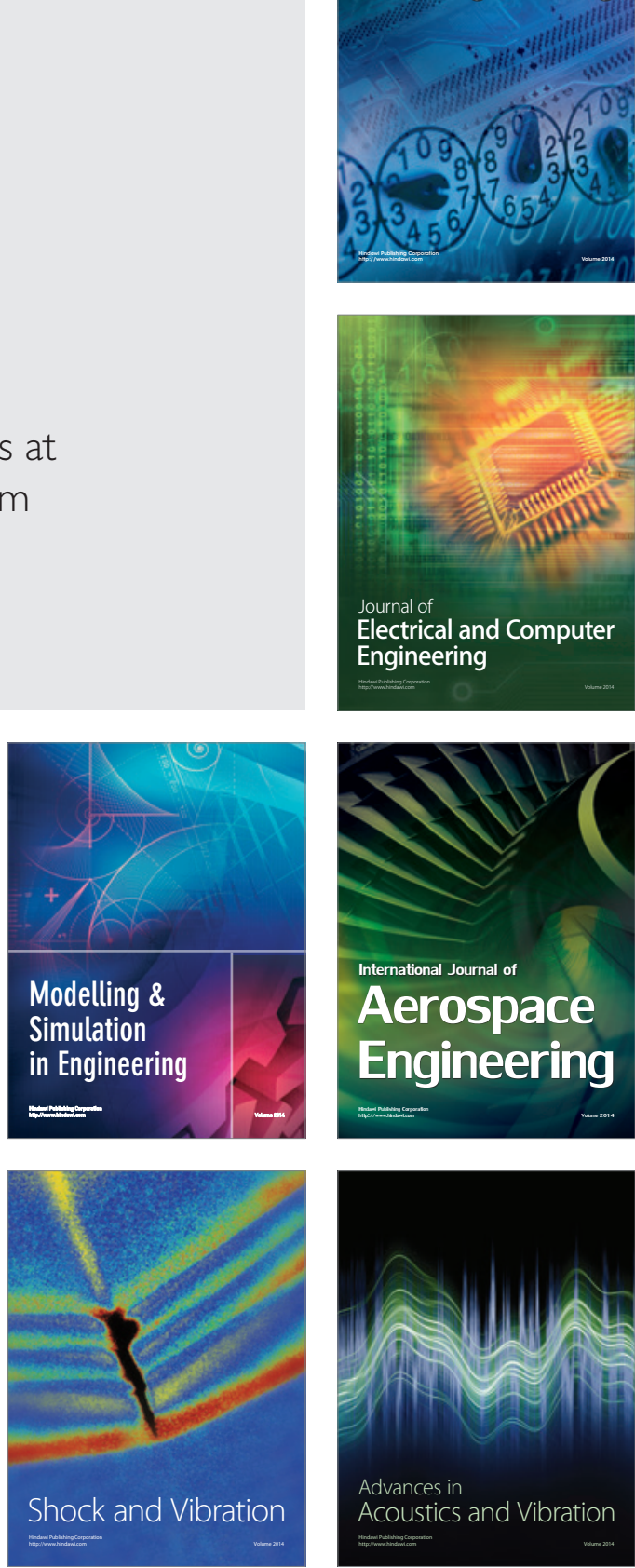